03

\title{
Метод повышения эффективности тепловой регенерации сенсора на основе силикалита: молекулярно-динамическое моделирование
}

\author{
() Д.С. Куцова, Е.В. Богатиков, А.Н. Шебанов, Е.Н. Бормонтов
}

Воронежский государственный университет,

Воронеж, Россия

E-mail: potanina.ds@gmail.com

Поступило в Редакцию 13 декабря 2018 г.

В окончательной редакции 13 декабря 2018 г.

Принято к публикации 16 января 2019 г.

\begin{abstract}
Методом молекулярной динамики обнаружена нелинейность температурной зависимости коэффициентов вероятности сорбции/десорбции в системе метан-силикалит. Предложен метод использования обнаруженной нелинейности для повышения эффективности десорбции метана из силикалита на основе осциллирующего нагрева. Полученные результаты могут быть использованы при тепловой регенерации газочувствительных сенсоров на основе цеолитов.
\end{abstract}

DOI: 10.21883/PJTF.2019.07.47541.17642

Силикалит - синтетический цеолит, обладающий широко развитой внутренней системой пор и каналов [1]. Его адсорбционные и селективные свойства, обусловленные структурными особенностями, в совокупности с доступностью и дешевизной позволяют рассматривать силикалит в качестве перспективного материала для газочувствительного слоя в газовых датчиках [2]. Одним из видов улавливаемого газа являются углеводороды, в частности метан. Необходимость детектирования последнего обусловлена его повсеместным использованием: в котельных и агрегатах, в автомобильной и химической промышленности, в быту.

При реализации сенсора на основе цеолита возникают трудности с эффективной регенерацией газочувствительного слоя. Сложная внутренняя структура силикалита препятствует свободному выходу адсорбированных молекул из внутрипорового пространства, что вызывает необходимость нагревания датчика до достаточно высоких температур. Как следствие, возникают проблемы теплоотвода и высокого энергопотребления.

Ранее в работе [3] методом молекулярной динамики были получены кривые сорбции и десорбции для системы метан-силикалит при различных температурах. На основе анализа кинетики сорбции/десорбции было высказано предположение о повышении эффективности десорбции при использовании осцилляций температуры относительно средней температуры тепловой регенерации силикалита.

Цель настоящей работы - численно показать реализуемость метода повышения эффективности тепловой регенерации силикалита в условиях, когда форма осцилляций температуры учитывает ограничения на скорость охлаждения силикалита.

Анализ процессов сорбции-десорбции проводился на основании следующей кинетической модели в рамках теории Ленгмюра [4]:

$$
d N_{s} / d t=w_{s}(T) N_{g}\left(N_{\max }-N_{s}\right) / N_{s}-w_{d}(T) N_{s} .
$$

Здесь $N_{s}$ - количество адсорбированных молекул, $N_{g}$ количество молекул в газовой фазе, $N_{\max }$ - предельная заполненность цеолита, $w_{s}(T)$ - вероятность адсорбции молекулы в единицу времени, зависящая от температуры, $w_{d}(T)$ - вероятность десорбции молекулы в единицу времени, зависящая от температуры.

Для определения значений $w_{s}(T), w_{d}(T)$ были проведены молекулярно-динамические расчеты в пакете LAMMPS [5]. Рассматривалась следующая система: решетка силикалита размером $2 \times 2 \times 2$ элементарные ячейки и 400 молекул метана (при давлении $\sim 1 \mathrm{~atm})$. Вид потенциального поля, используемый при молекулярно-динамическом моделировании [3], обеспечивал воспроизведение подвижности каркаса цеолита и структур молекул. Кинетика десорбции метана силикалитом исследовалась в температурном диапазоне

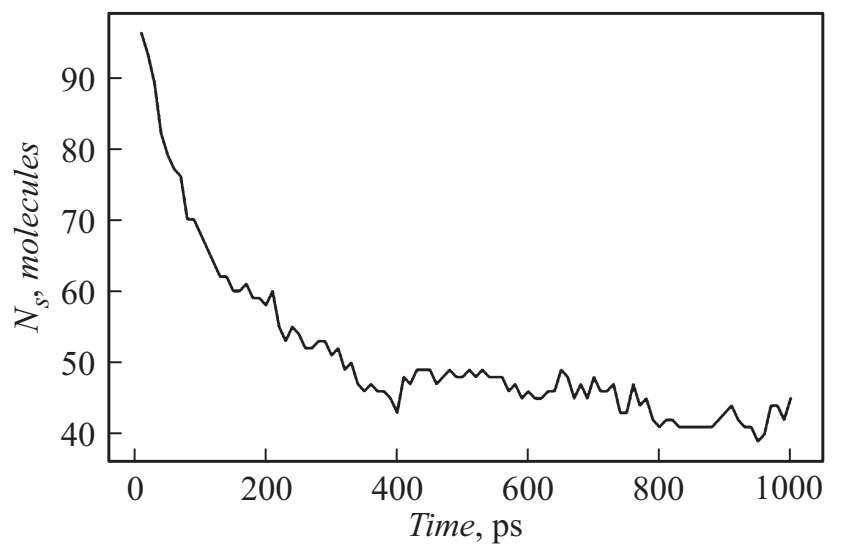

Рис. 1. Кинетика процесса десорбции метана из силикалита, $T=423 \mathrm{~K}$ (результаты молекулярно-динамического моделирования). 


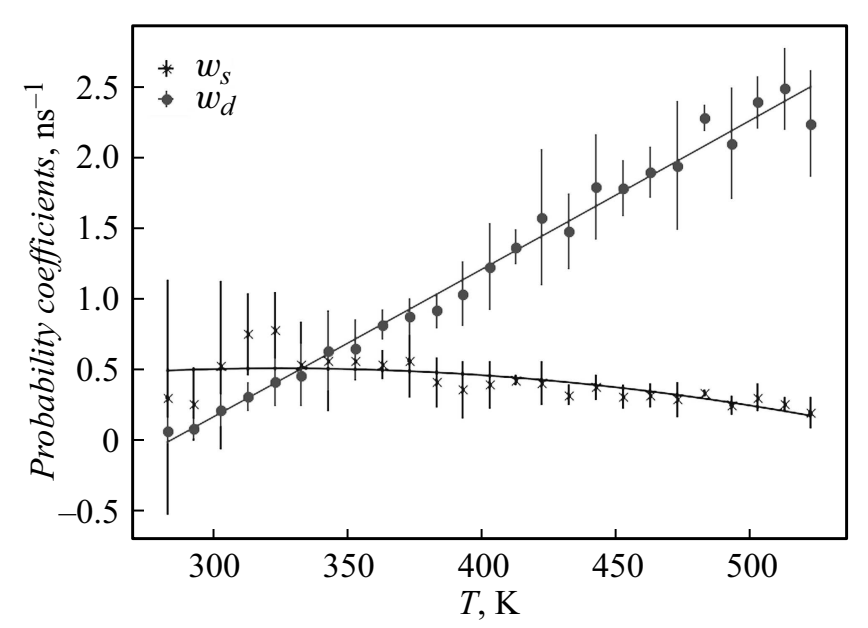

Рис. 2. Температурные зависимости коэффициентов вероятности сорбции $w_{s}(T)$ и десорбции $w_{d}(T)$.
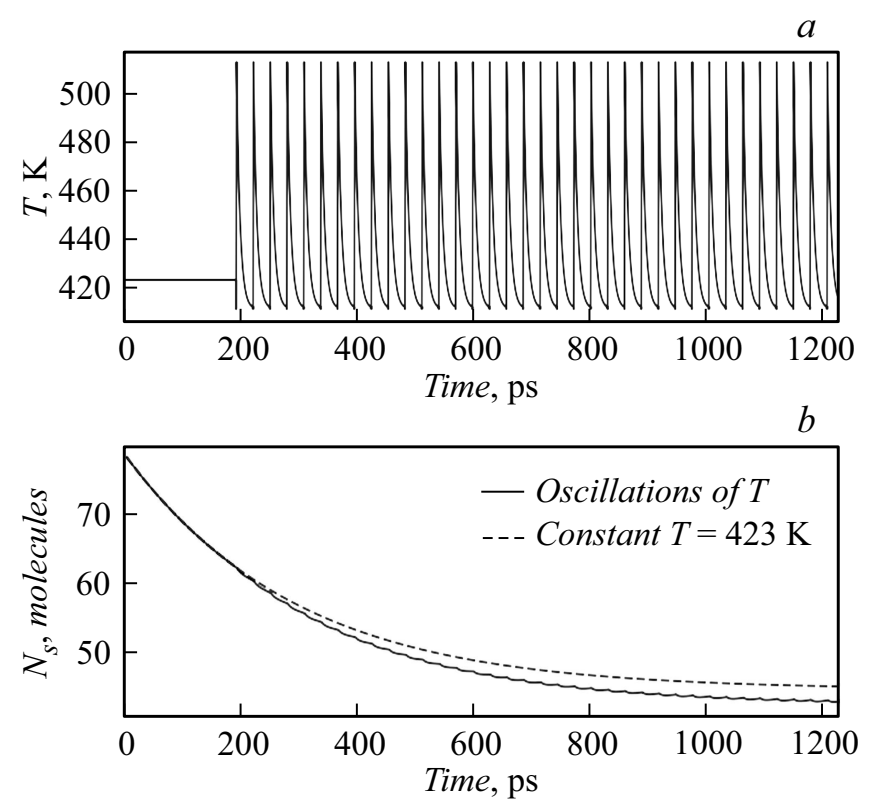

Рис. 3. Повышение эффективности десорбции при использовании тепловых осцилляций. $a-$ форма температурных осцилляций; $b-$ теоретические кривые зависимости числа адсорбированных молекул $N_{s}$ от времени при постоянной температуре $T=423 \mathrm{~K}$ и при наличии температурных осцилляций со средней температурой $T=423 \mathrm{~K}$.

от 283 до $523 \mathrm{~K}$ с шагом $10 \mathrm{~K}$. В качестве начального состояния использовались результаты расчетов адсорбции в системе со следующими параметрами: ансамбль $N V T$ (постоянные число частиц, объем и температура системы), температура $273 \mathrm{~K}$, шаг моделирования 1 ps, количество шагов $10^{6}$. Для процесса десорбции в каждой температурной точке указанного диапазона проводилось по пять вычислительных экспериментов с аналогичными параметрами.

По временны́м зависимостям $N_{S}(T)$ (рис. 1), полученным в результате вычислительных экспериментов, были определены значения коэффициентов вероятностей $w_{s}(T)$ и $w_{d}(T)$ и построена их температурная зависимость, аппроксимированная кривой второго порядка (рис. 2). На основании полученных температурных зависимостей $w_{s}(T)$ и $w_{d}(T)$ численно решалось уравнение (1) в условиях осциллирующей температуры.

В модели использовался быстрый линейный нагрев (который может быть реализован, например, лазером) и медленное экспоненциальное охлаждение в соответствии с законом Ньютона

$$
T(t)=T_{e n v}+\exp (-t / \tau)\left(T(0)-T_{e n v}\right),
$$

где $T_{e n}$ - температура окружающей среды, $T(0)-$ температура силикалита в момент начала охлаждения, $\tau-$ постоянная времени. Значение постоянной времени $\tau=6$ ps выбиралось на основе тепловой инерционности кристалла цеолита по формуле

$$
\tau=l^{2} / \alpha
$$

Здесь $l-$ протяженность кристалла в направлении теплопереноса, $\alpha$ - коэффициент температуропроводности силикалита.

Используемый период осцилляций $T_{o s c}=30 \mathrm{ps}$ определялся по кривой десорбции как время, на протяжении которого скорость десорбции максимальна. Увеличение периода осцилляций из-за снижения скорости десорбции сопровождается снижением эффективности использования температурных осцилляций. При выбранных параметрах нагрева $\tau$ и $T_{o s c}$ обеспечивались диапазон изменения температуры $T=411-523 \mathrm{~K}$ и средняя температура системы $423 \mathrm{~K}$ (рис. 3, a).

Полученная зависимость числа адсорбированных молекул от времени представлена на рис. $3, b$. Здесь же изображена зависимость, полученная при постоянной температуре $423 \mathrm{~K}$.

Уменьшение числа адсорбированных в силикалите молекул при осцилляциях температуры показывает эффективность предложенной методики. Полученный результат может быть интересен при практической реализации газочувствительных сенсоров либо для повышения их чувствительности, либо для повышения их быстродействия.

\section{Список литературы}

[1] Брек Д. Цеолитовые молекулярные сита. М.: Мир, 1976. $781 \mathrm{c}$.

[2] Reib S., Hagen G., Moos R. // Sensors. 2008. V. 8. P. 7904-7916.

[3] Куцова Д.С., Богатиков Е.В., Шебанов А.Н., Куликов Д.Г., Бормонтов Е.Н. // Вестн. Воронеж. гос. техн. ун-та. 2017. T. 13. № 5. C. $108-112$.

[4] Булярский С.В., Басаев А.С. // Нано- и микросистемная техника. 2009. Т. 113. № 12. С. 7-21.

[5] Plimpton S. // J. Comput. Phys. 1995. V. 117. P. 1-42. 